


\title{
Procesos de identización en el arte contemporáneo: construir una identidad colectiva a través de una cartografía identitaria en la red*
}

\author{
IDENTIZATION PROCESSES IN CONTEMPORARY ART: CONSTRUCTING \\ A COLLECTIVE IDENTITY THROUGH AN IDENTITARY CARTOGRAPHY \\ IN THE NETWORK
}

PROCESSOS DE IDENTIZAÇ̃̃O NA ARTE CONTEMPORÂNEA: CONSTRUIR UMA IDENTIDADE COLETIVA A INCLINAÇÃO DE UMA CARTOGRAFIA IDENTITARIA NA REDE

\section{Carmen Gómez Redondo** Olaia Fontal Merillas***}

Cuadernos de Música, Artes Visuales y Artes Escénicas / Volumen 12 - Número 2 / Julio - Diciembre de 2017 / ISSN 1794-6670/ Bogotá, D.C., Colombia / pp. 299-319

Fecha de recepción: 26 de mayo de 2015 Fecha de aceptación: 1 de agosto de 2016 Disponible en línea: 22 de junio de 2017 doi:10.11144/Javeriana.mavae12-2.piac

\footnotetext{
* Artículo de investigación. Sintetiza parte de la tesis doctoral Procesos de patrimonialización en el arte contemporáneo: diseño de un artefacto educativo para la identización, defendida por Carmen Gómez y dirigida por Olaia Fontal. Asimismo, se inscribe en los proyectos de investigación EDU2012-37212 y EDU2015-65716-C2-1-R, financiados por el Ministerio de Economía y Competitividad del Gobierno de España.

* Doctora en Educación por la Universidad de Valladolid. Profesora Ayudante en el área de Didáctica de la Expresión Plástica de la Universidad de Valladolid.

** Doctora en Ciencias de la educación. Profesora Titular de Universidad en el área de Didáctica de la Expresión Plástica en la Universidad de Valladolid.
} 


\section{Resumen}

Según las propuestas de la nueva museología y la educación patrimonial, se pretende profundizar, desde la perspectiva educativa, en los procesos de identización en el arte contemporáneo. Este estudio tiene como objetivo mostrar el arte contemporáneo como herramienta para la generación de identidades colectivas y así cumplir con la función social y cultural del arte que se plantea desde las posturas teóricas. Para ello, se ha diseñado una acción educativa con una actividad clave: una cartografía identitaria virtual donde los participantes generan un mapa de la identidad colectiva entramada por ellos a partir de elementos patrimoniales individuales que comparten y consensuan. Para el diseño y desarrollo de esta investigación, se ha empleado el método etnográfico que parte de la observación para la recogida de datos y el análisis de contenido de tipo cualitativo para la interpretación de los datos. De todo ello se obtienen dos principales resultados: en primer lugar, la construcción consciente de una identidad del grupo, en la que tienen cabida los elementos patrimoniales trabajados; y en segundo lugar, la importancia de la afectividad en la creación de lazos identitarios. Las conclusiones de este trabajo van encaminadas a la puesta en valor de la mediación educativa en los procesos de patrimonialización e identización como elemento para producir un cambio en las personas y como contexto para la investigación. Así pues, las aportaciones que realiza esta investigación se centran en los procesos de identización como paso siguiente a la patrimonialización con una propuesta educativa que hace hincapié en los vínculos entre personas y objetos.

Palabras claves: arte contemporáneo; identidad; patrimonio cultural; didáctica del museo; procesos de identización

\section{Abstract}

Based on the proposals of the new museology and heritage education the aim is to deepen, from an educational perspective, in the identization processes in contemporary art. This study aims to show contemporary art as a tool for the generation of collective identities, thus fitting in the social and cultural function of art that arises from the theoretical positions. For this purpose, we have designed an educational action with a key activity: a virtual identity mapping where participants create a map of collective identity lattice them from individual heritage that they share and discuss together. For the design and development of this research it has been used the ethnographic method that starts from the observation of a data collection and content analysis of qualitative type for the interpretation of the data. From all the information they are obtained two main results: the first one, the conscious construction of a group identity, where the worked heritage elements have a place and the second one, the importance of affectivity to create identity ties. The conclusions of this work are directed to the value of educational mediation in the processes of patrimonialization and identization, as an element to produce a change in people and as a context for research. Thus the contributions made by this research focus on the processes of identification as a next step to patrimonialisation through an educational proposal that emphasizes the links between people and objects.

Keywords: contemporary art; identity; cultural heritage; museum education; identization processes.

\section{Resumo}

Com base nas propostas da nova museologia e património educação é aprofundar, a partir de uma perspectiva educacional processos identização na arte contemporânea. Este estudo tem como objetivo mostrar

a arte contemporânea como uma ferramenta para a geração de identidades coletivas, cumprindo assim a função social e cultural de arte que surge das posições teóricas. Para isso criamos uma ação educativa com uma actividade fundamental: um mapeamento de identidade virtual onde os participantes criam um mapa de identidade coletiva retículo-los de ativos individuais para compartilhar e concorda juntos. Para a concepção e desenvolvimento desta pesquisa foi utilizado o método etnográfico de observação para coleta de dados e análise de conteúdo para a interpretação qualitativa dos dados. Tudo isso são obtidos dois resultados principais: em primeiro lugar, a construção consciente de uma identidade de grupo, em que alguns dos ativos trabalhistas e em segundo lugar, a importância da emoção na criação de laços de identidade. As conclusões deste trabalho visam o reforço da educação processos de mediação patrimonialização e identização como um elemento para produzir uma mudança nas pessoas e como um contexto para a investigação. Assim, as contribuições feitas por este foco de pesquisa em processos identização como após a patrimonialização através de uma proposta educacional que enfatiza as ligações entre pessoas e objetos etapa.

Palavras chave: arte contemporânea; identidade; herança cultural; educação em museus; processos identização 


\section{INTRODUCCIÓN}

A lo largo del siglo XX muchos son los cambios paradigmáticos que han ocurrido en torno a la conceptualización del museo que han derivado en la formulación de una nueva museología (Rivière 1993). Uno de los principios básicos de esta nueva corriente pone el acento en lo humano y se aleja de la hegemonía de la colección (Hooper-Greenhill 1998); el museo comienza a desarrollar modelos educativos, que no solo acercan el arte a un perfil más amplio de públicos, y lo adapta a sus necesidades, sino que más allá de ello se plantea la acción social a través del arte (Levi 1985). Esto es, el museo del siglo XXI, como consecuencia de los movimientos paradigmáticos del siglo XX, no solo acerca su colección a diversidad de públicos, sino que la emplea como herramienta o medio para la generación de nuevas inercias sociales y culturales.

Este cambio paradigmático del museo afecta, por tanto, la conceptualización del patrimonio. El bien cultural, ante esta nueva mirada, deja de tener valor intrínseco y se configura como símbolo en continua construcción por parte de las personas que lo significan; el patrimonio es consecuencia de un valor que se atribuye (Ballart y Tresserras 2001). Desde este punto de vista, la educación patrimonial toma relevancia como clave para la relación entre los individuos y los elementos potencialmente patrimoniales.

Situar el acento en el sujeto que aprende constituye una de las especificidades de la educación, frente al tratamiento de otros cuerpos disciplinares que, como la gestión, el turismo, la política o la economía, se ocupan más de la intervención en el patrimonio, de la emisión o del propio mensaje, y favorece una mediación efectiva entre la emisión y la recepción o, lo que es igual, entre patrimonio y sociedad (Fontal 2003, 178).

La educación patrimonial es aquí la perspectiva de enfoque desde la que proponer la experiencia educativa que marca este trabajo, cuyo objetivo principal es generar una identidad colectiva en el grupo a través del arte contemporáneo, ya que una de las principales aportaciones del patrimonio es su capacidad para configurarse como seña identitaria del grupo y, por tanto, actuar como conglomerante de las identidades culturales.

Hablamos, por ende, de detonar procesos sociales y culturales a través de la educación patrimonial, empleando para ello metodologías basadas en los procesos de identización (GómezRedondo 2011), que se definen como un proceso dinámico de construcción de la identidad en diálogo con el entorno, y donde el individuo es agente activo de la construcción. Para ello, se establece una secuencia significativa para la identización en entornos patrimoniales que nos lleva, desde el ámbito educativo, a la construcción de identidades individuales y colectivas a través del patrimonio por medio de los procedimientos: conocer-comprender-respetar-valorarpatrimonializar-identizar (nivel individual)-compartir-consensuar-identizar (nivel colectivo) (GómezRedondo 2012). Esta secuencia, que hunde sus raíces en la secuencia procedimental para la patrimonialización enunciada por Fontal (2003), servirá como esqueleto para el diseño didáctico.

La actividad clave del diseño didáctico para la generación de la identidad grupal es la cartografía identitaria elaborada en una página web. Esta cartografía resulta ser un mapa de imágenes y vínculos que simbolizan los patrimonios individuales y su proceso de colectivización. Su potencial reside en que permite dar visibilidad a los procesos abstractos descritos en la secuencia. Con esta actividad, los participantes no solo aportan elementos patrimoniales individuales a la colectividad, sino que dejan patentes vínculos afectivos, cognitivos, estéticos, sociales, etc., y además los procesos culturales que configuran la identización colectiva, como el consenso, la compartición o la identización individual y colectiva. 


\section{LA COMUNIDAD DE INTERPRETACIÓN DE LA IDENTIDAD INDIVIDUAL A LA IDENTIDAD COLECTIVA}

La acción educativa en el entorno patrimonial se entiende, entonces, como un contexto detonante de los procesos de identización (Gómez-Redondo 2011). Con esta acción, los individuos pueden relacionarse y vincularse con su patrimonio, pero, a su vez, establecer procesos de identización colectiva, es decir, encontrarse con los otros, e incluso formar un nosotros a través del patrimonio, como vínculo, como canal y como contexto.

La comunidad no se define tanto como un grupo o como un conjunto de personas que se establecen cercanamente, sino que son personas con algo en común y es según estos rasgos comunes que nace el concepto de comunidad. Si el individuo, en cierto modo, se define por contraste con el entorno, la comunidad se define por la semejanza con el entorno y, en este sentido, el museo puede ser entendido como comunidad de aprendizaje (Álvarez-Rodríguez 2007).

Con la educación patrimonial y de la actividad diseñada, los individuos comienzan a dotar el patrimonio de significados, estos los relacionan con su propia experiencia y el conocimiento del entorno que tienen y forman aprendizajes significativos. Pero es en la puesta en común, en el diálogo continuo o esporádico, entre los individuos que conforman el taller, donde comienzan a articularse rasgos comunes. Se comparte y se consensua lo aportado por cada individuo, comienza un discurso común a todos los participantes; hablamos, pues, de una "comunidad de interpretación en la configuración de significados a partir de las propias experiencias, cuando se plantea una labor de mediación adecuada" (Aguirre 2008, 110).

Esta interpretación no queda estanca, sino que, al significarse con la experiencia propia y, a la vez, elaborarse con la experiencia común que se está generando, comienza a adquirir un sentido dentro del individuo y la comunidad generada, empieza a configurarse un sentimiento de pertenencia. Como vemos, el patrimonio no solo permite generar vínculos entre elementos y personas, sino también entre las propias personas a través de los elementos patrimoniales. Al establecer vínculos e interacciones entre personas, podemos hablar, por tanto, de comunidad conformada bajo el acuerdo común (Valle Flórez 2011).

Por tanto, el museo como espacio para la generación de comunidades participa como agente de la cultura, tiene un papel activo para con ella, ayuda a contextualizar el entorno, a interpretarlo, actuando como catalizador de procesos culturales. Pero no solo eso, sino que adquiere un papel clave para comprender los cambios de nuestra sociedad. Con diseños educativos específicos para estos contextos (como el que aquí mostramos), es posible generar inercias sociales, no solo a través de la consecución de productos sociales (nuevas identidades y vínculos afectivos entre personas), sino que se toma conciencia de los procesos necesarios para su construcción. Por tanto, la acción educativa en el museo no solo genera productos sociales y culturales, sino que contribuye a la adquisición de herramientas y competencias para la creación de dinámicas sociales y culturales. 


\section{ARTEFACTO: UNA PROPUESTA PRÁCTICA PARA LA CONSTRUCCIÓN DE IDENTIDADES COLECTIVAS}

Es en el contexto de la acción educativa en el museo, y en la búsqueda de construcciones identitarias donde nace la propuesta del ARTEfacto. Este se define como la culminación de una propuesta educativa para la creación de identidades colectivas, es decir, de una comunidad en el museo. Sin embargo, no se agota en este espacio, sino que, en la búsqueda de una significatividad de la acción dentro de la cotidianidad y la historia personal de los participantes, se proyecta al exterior de los muros del museo.

\section{ORIGEN Y OBJETIVOS DE LA INVESTIGACIÓN}

Esta investigación nace, por una parte, de la necesidad de observar los procesos y procedimientos que generan vínculos identitarios a través del patrimonio, desde la acción educativa. Pero, por otra parte, surge del interés por generar vínculos identitarios en los grupos formativos universitarios. Ambos problemas originan una investigación destinada a observar los fenómenos identitarios a través de un diseño educativo generado para tal efecto: el taller "Construirse a través de la obra de Esteban Vicente".

\section{CONTEXTUALIZACIÓN Y MUESTRA}

Parte del problema de la investigación viene determinado por el contexto. De manera general, en el entorno universitario, confluyen personas de diversos orígenes, la búsqueda de nuevos grupos de amigos y compañeros es una de las principales inquietudes afectivas en los primeros años de estudio. Por ello, se considera interesante generar inercias para la generación de grupos e identidades colectivas a través de la realización de actividades, en este caso extraacadémicas.

Para ello, se diseña una acción educativa por llevar a cabo en el Museo Contemporáneo Esteban Vicente. El centro seleccionado es un museo monográfico dedicado a la obra del autor segoviano (que se caracteriza por su desarrollo plástico en el contexto del expresionismo abstracto en los Estados Unidos), cuyo consorcio es público-privado y cuenta con la participación del Ayuntamiento de Segovia, la Diputación de Segovia, el Ministerio de Educación, Cultura y Deporte, la Junta de Castilla y León y The Harriet and Esteban Vicente Foundation. Aunque el museo cuenta con un departamento de educación propio, en esta ocasión, cede los espacios para la realización de la actividad, pero su impartición y desarrollo queda a cargo de la educadora/investigadora.

Esta actividad se oferta a los alumnos de la Facultad de Educación de Segovia (Universidad de Valladolid) que reúnen una serie de características definitorias:

- Comprenden un rango de edad en la que aún están en proceso de cambio significativo de su identidad individual.

- Su bagaje identitario y las señas de identidad que poseen en términos subjetivos tienen un alto grado de compartición.

- Son, en su gran mayoría, inmigrantes de otras ciudades, para los que este entorno resulta totalmente desconocido y la Facultad resulta su gran centro de socialización. 
Según esta acotación del campo, se formaliza una propuesta de participación abierta a los alumnos de segundo curso del Grado en Educación Infantil, en la que finalmente participan once personas. De ellas, diez son estudiantes de dicho grado y una de curso de adaptación a grado (que además es la única persona que tiene otro tipo de estudios además de los cursados, en este caso Licenciatura en Historia del Arte). La edad oscila entre 20 y 27 años, y respecto de su origen, cuatro miembros tienen su domicilio familiar fuera de Segovia y siete son de la provincia de Segovia, con lo cual tan solo dos miembros tienen su domicilio familiar en la capital de la ciudad.

Así pues, el grupo humano que conforma la comunidad del taller es un grupo de, predominantemente, mujeres jóvenes (dos miembros son hombres), de entre 20 y 27 años, residentes de forma temporal en Segovia; en su mayoría estudiantes del Grado en Educación Infantil que presentan, a priori, referentes identitarios y culturales comunes o similares, y por tanto podríamos decir que es un grupo homogéneo.

\section{DISEÑO EDUCATIVO}

Antes de la realización del ARTEfacto, se realiza una serie de actividades para la patrimonialización e identización individual de las obras de Esteban Vicente. Estas actividades se llevan a cabo en el propio museo en dos sesiones de tres horas cada una. Cada sesión estaba precedida de una visita por el museo, en las que se rompe con el tradicional estatus docente/ transmisor y participantes/receptores. Aquí son los propios participantes los que eligen las obras en las que se centran y generan discursos propios sobre los significados de las obras. La vinculación con la experiencia previa (Calaf 2009) y las metodologías participativas que implican al individuo (Juanola y Calbó 2004) son la clave en este primer cuerpo del diseño. Así, a través de la común interpretación, se genera la comunidad de interpretación (Gómez-Redondo 2013). Tras la visita, se sucede una serie de actividades relacionadas con el conocimiento, el respeto, la valoración y la patrimonialización de la obra del artista, pero de manera paralela se trabajan, además, el autoconocimiento, la propia definición y la construcción consciente de la identidad individual (Rodrigo 2009). Estas actividades se llevan a cabo a través de estrategias como la ejemplificación, discusión/conversación o la metáfora (generalmente visual, para la comprensión de los procesos abstractos). Tras la secuencia de actividades preparatorias, se lleva a cabo la cartografía identitaria en la red.

\section{EL ARTEFACTO IDENTITARIO}

A través de la página web www.artefacto.com.es (inhabilitada), se genera un espacio de relación y diálogo visual entre los participantes y se desarrollan procedimientos relativos a la identización colectiva. Este contexto, denominado cartografía identitaria, es un espacio en evolución que muestra en forma de diagrama o mapa de relaciones las diversas señas identitarias que, a través de narrativas personales, proponen para el consenso los diversos miembros de la comunidad.

Al comenzar la actividad, esta página web tan solo contiene una imagen del grupo y es, a través del envío por correo electrónico a lo largo de treinta días, que se suben y relacionan las diferentes narrativas y se forma un mapa de relaciones que va configurando las señas identitarias de la comunidad. 
Las comunidades pueden ser más o menos virtuales, conforme al equilibrio entre la interacción física y las interacciones mediatizadas. No es apenas la tecnología que crea y caracteriza la comunidad, mas la tecnología tiene la virtud de modificar y relativizar el espacio y el tiempo, modificando también las relaciones entre los seres humanos. [...] Las comunidades de aprendizaje pueden incrementar considerablemente su eficacia cuando utilizan las tecnologías digitales para consolidar las redes de interacción y comunicación en su seno para promover y potenciar el aprendizaje de los sus miembros. (Meirinhos y Osório 2009, 47-48)

A través del correo electrónico, se envían las imágenes con una tabla de relaciones completada (tabla 1), para que sean subidas a la página web por el gestor de la página. De este modo, la web se va actualizando cuando se envía un nuevo archivo que se completa y se relaciona cada vez de manera más compleja. Cada miembro comparte visiones subjetivas de su realidad, que son legitimadas y ratificadas con el consenso, el cual se traduce en relaciones de semejanza u oposición y afectividad a modo de votación. Esta actividad supone la materia base para la construcción de una cartografía que pretende ser metáfora de un proceso invisible y abstracto, de tal forma que con la visualización del proceso y el producto, los miembros del grupo puedan significarse a través de él. En dicho constructo, se observan las señas de identidad compartidas por los miembros, el proceso de consenso y la imagen cartográfica de las relaciones producidas.

\section{TABLA 1. TABLA DE VÍNCULOS QUE ACOMPAÑA A CADA NARRATIVA}

\begin{tabular}{|c|c|c|c|}
\hline Nombre del autor & & & \\
\hline \multicolumn{4}{|l|}{ Título } \\
\hline \multicolumn{4}{|l|}{ Breve explicación } \\
\hline \multicolumn{4}{|c|}{ Otra/s narrativa/s con las que se relaciona } \\
\hline \multirow[b]{2}{*}{ Relación según } & \multicolumn{3}{|c|}{ Valoración de la relación } \\
\hline & $\begin{array}{l}\text { Mucha } \\
\text { semejanza }\end{array}$ & $\begin{array}{l}\text { Poca } \\
\text { semejanza }\end{array}$ & $\begin{array}{l}\text { Total } \\
\text { oposición }\end{array}$ \\
\hline \multicolumn{4}{|c|}{ Afectividad hacia lo narrado o hacia el autor } \\
\hline \multicolumn{4}{|c|}{$\begin{array}{l}\text { Semejanza en el concepto } \\
\text { o en su representación }\end{array}$} \\
\hline \multicolumn{4}{|c|}{ Semejanza en sensaciones o emociones } \\
\hline Semejanza simbólica & & & \\
\hline
\end{tabular}

Partiendo de una imagen aportada por la investigadora, relacionada con la obra de Esteban Vicente, que sirve a modo de ejemplo y base para la producción de relaciones (teniendo en cuenta que las siguientes narrativas pueden no relacionarse con ella y por tanto es susceptible de no ser ratificada ni de constituirse como seña de identidad de la identización colectiva), se establecen lazos a modo de mapa, entre las aportaciones de los miembros, siguiendo un código de representación que concuerde con las valoraciones de cada autor para con las relaciones establecidas: 
- En color verde, la relación según la afectividad hacia lo narrado o el autor.

- En color rosa, la relación según la semejanza con el concepto o la representación.

- En color azul, la relación según la semejanza de emociones o sensaciones.

- En color amarillo, la relación según la semejanza simbólica.

Aparecen, además, gradientes, en estos tipos: una línea fina define poca semejanza, una línea gruesa mucha semejanza y una línea discontinua define la total oposición. De este modo, las diversas señas generadas son ratificadas por el resto del grupo a través del resto de relaciones pudiendo decirse que, a más cantidad de relaciones, mayor consenso sobre las señas generadas.

El resultado de esta estrategia es un constructo, un ARTEfacto identitario, en continua transformación que retroalimenta las experiencias y el background identitario de cada miembro respecto de su identidad colectiva.

Así pues, a través de esta comunidad virtual, nace una construcción de la identidad de la comunidad que profundiza en la agencia individual hacia la construcción comunitaria. De este modo, el contexto virtual resulta metáfora del proceso cultural de objetivación; cada miembro, desde su contexto real y subjetivo, formula narrativas identitarias, bajo la premisa de la objetivación, es decir, de la formulación desde la creencia de una seña de identidad común a todos, no solo al individuo. Esa narración se objetiva y descontextualiza en la virtualidad, donde lo subjetivo desaparece, y las señas, cargadas de impronta individual, resaltan en un espacio sin significado, que va cobrando sentido en su construcción. El contexto físico y el contexto virtual se configuran como metáfora del proceso social de objetivación formulado ya por Berger y Luckmann (2001).

\section{METODOLOGÍA DE INVESTIGACIÓN}

Como se ha enunciado al comienzo de este apartado, el diseño didáctico forma parte de una investigación destinada a observar los procesos de identización en el contexto de una acción educativa diseñada a tal efecto. Para llevar a cabo y registrar el fenómeno observado, se emplea el método etnográfico, ya que el centro de la investigación es la observación cualitativa del fenómeno. Se recogen datos por medio de siete instrumentos: registro videográfico, grabación de sonido, diario de campo, cuaderno de bitácora, registro fotográfico, productos artísticos y la propia cartografía identitaria. Los siete instrumentos son manejados desde tres tipos de visiones distintas: 1) una visión interna (participantes), 2) una visión externa (educadora) y 3) una visión neutra (observadora externa). Los instrumentos son empleados, de manera general, por todas las visiones; sin embargo, algunos de ellos son específicos de cada visión, lo cual permite una triangulación de los resultados no solo instrumental sino también por niveles combinados.

Finalmente, para el análisis de datos, se emplea software específico que permite el análisis de contenido de tipo cualitativo, formulado a tres niveles: 1) enunciativo, 2) descriptivo y 3 ) interpretativo (figura 1). 


\section{RESULTADOS DE CARTOGRAFIAR LA IDENTIDAD COLECTIVA}

Con las aportaciones realizadas por los participantes, es posible establecer el mapa de relaciones al que hacemos referencia. Así pues, las imágenes se disponen en el espacio unidas a través de líneas que representan los nexos o las relaciones que vinculan las imágenes entre sí. A medida que evoluciona la cartografía, es posible observar cómo aparecen procesos de colectivización y de identización, como compartir y consensuar, de manera que se van generando unos nodos discursivos, es decir, ideas o temas que son tratados en más narrativas que se vinculan más frecuentemente entre ellos (figuras 2-3).

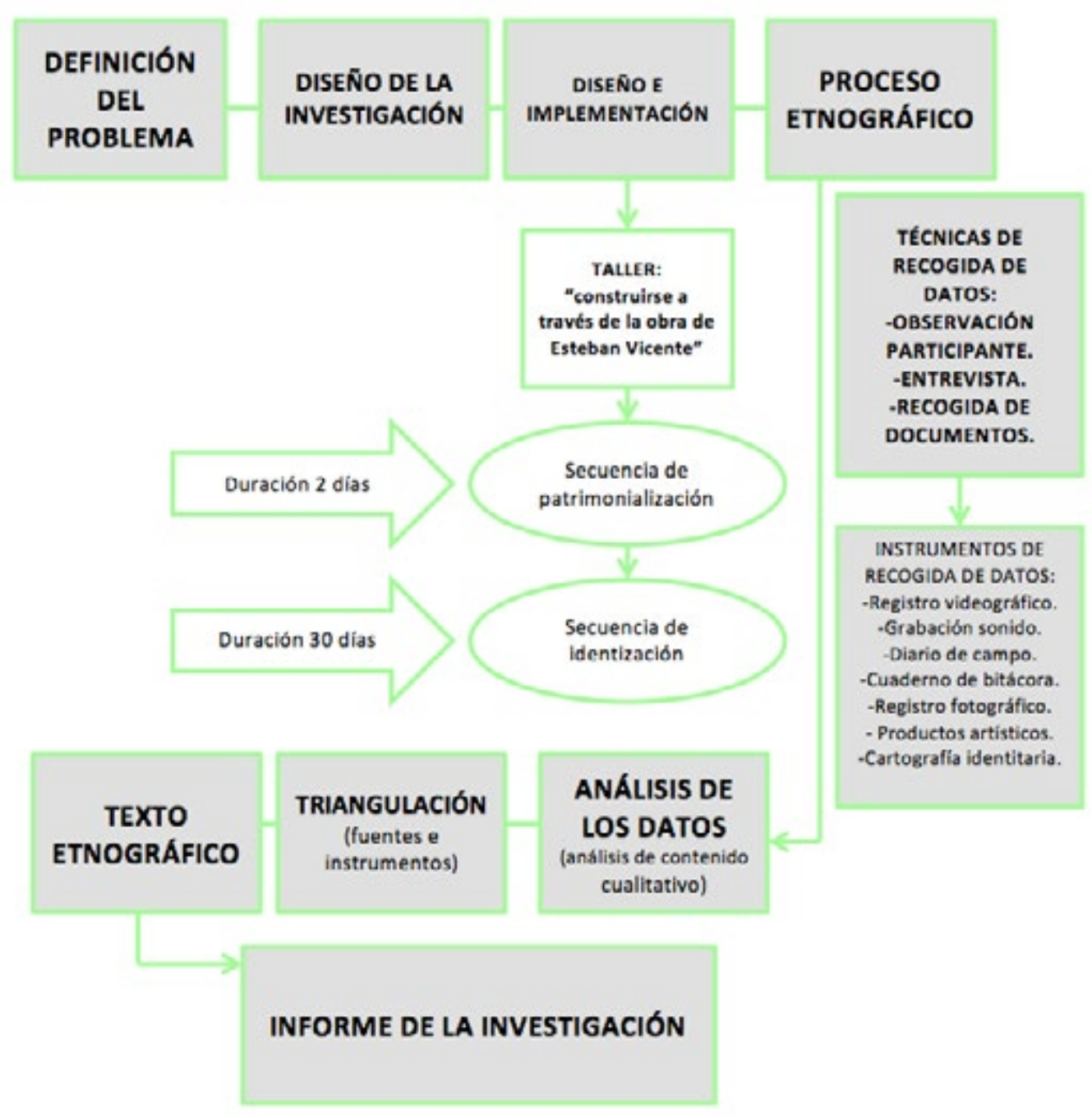

Figura 1. Diseño del proceso de la investigación

Fuente: Elaboración propia. 


\section{ARY facto}

cartografia ideatitaria

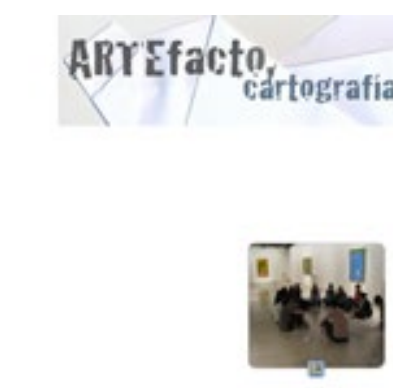

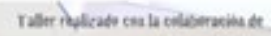



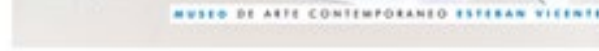

Figura 2. María del Carmen Gómez-Redondo: ARTEfacto: cartografía identitaria, 2013. Fuente: www.ARTEfacto.com.es
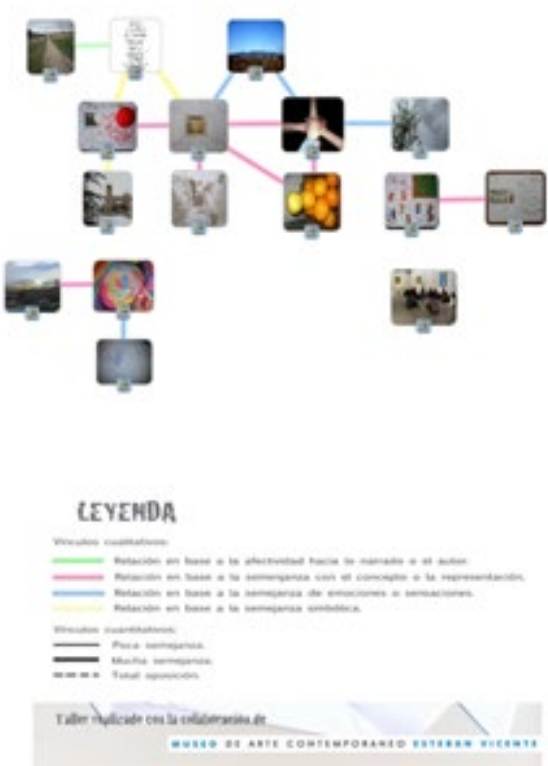

Figura 3. María del Carmen Gómez-Redondo: ARTEfacto: cartografía identitaria, 2013. Fuente: www.ARTEfacto.com.es

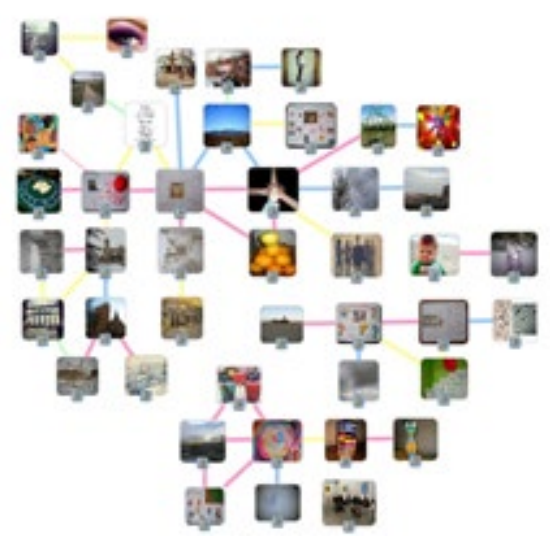

Figura 4. María del Carmen Gómez-Redondo: ARTEfacto: cartografía identitaria, 2013. Fuente: www.ARTEfacto.com.es 
A través de estas imágenes, que muestran la evolución de la cartografía, es posible observar estos nodos temáticos que, al finalizar la actividad, se configuran como señas identitarias del grupo. Estos nodos vienen descritos por los tipos de vínculos creados que, según la codificación generada, podríamos decir que se basan principalmente en relaciones de semejanza simbólica o semejanza directa con el concepto o representación y, en menor medida, aparecen las relaciones según la semejanza de emociones o sensaciones. Además, la mayoría de los participantes entiende que existe una gran semejanza, apareciendo en menor medida relaciones de poca semejanza y sin existir relaciones de total oposición.

Finalmente, de lo observado a lo largo del desarrollo de esta estrategia, se puede inferir que aparece una inercia de consolidación, es decir, las narrativas tienden a relacionarse formando un gran cuerpo y conectando los nodos aislados que se formaron en el inicio. Como se observa en la figura 4, tan solo aparece un nodo aislado en la parte inferior derecha y una imagen aislada sin conexión que resulta ser la imagen detonante inicial propuesta desde la perspectiva externa.

RYEfacto Cártografia ideatitaria
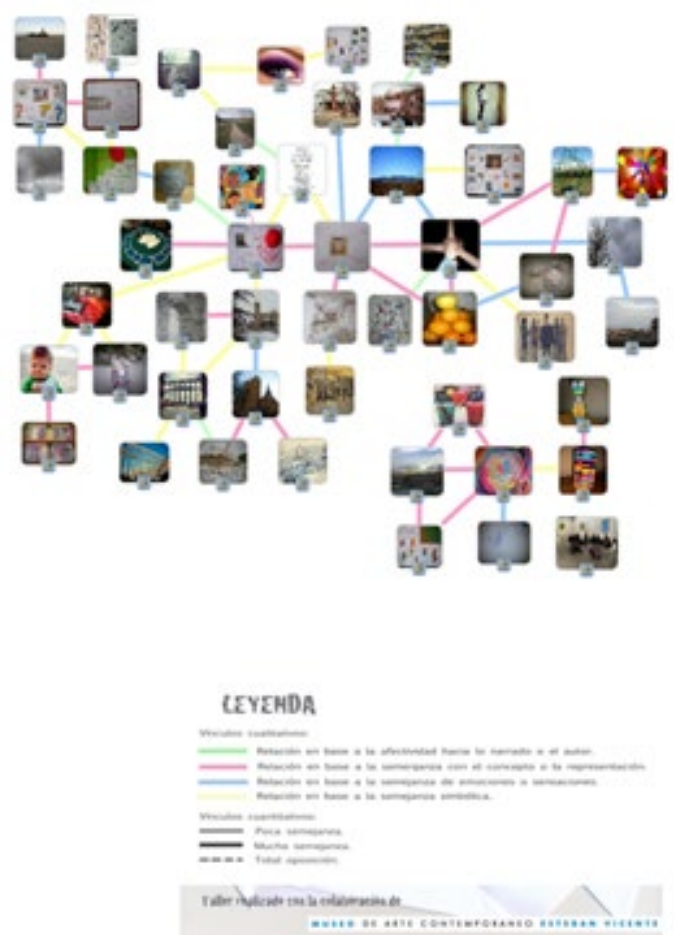

Figura 5. María del Carmen Gómez-Redondo: ARTEfacto: cartografía identitaria, 2013. Fuente: www.ARTEfacto.com.es

Por otra parte, en general, las imágenes se formulan como símbolos de conceptos más elaborados y se alejan de la narrativa visual para apoyarse en el texto aclaratorio. Estos conceptos se repiten con frecuencia y se forma entonces un nodo conceptual marcado por imágenes que remiten, con matices, a una noción común. A continuación, se describen los conceptos clave en torno a los que giran estos nodos. 
Este hecho queda anclado en la cartografía por narrativas como Inseguridad contemporánea, Incógnitas o Manchas que nos unen (figuras 5-7).

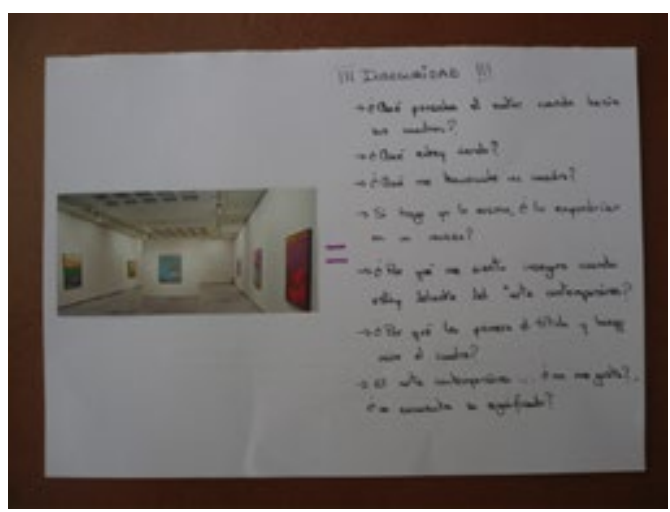

Figura 6. Anónimo: Inseguridad contemporánea, 2013, collage, 29×42 cm. Fuente: Gómez-Redondo $(2013,591)$.

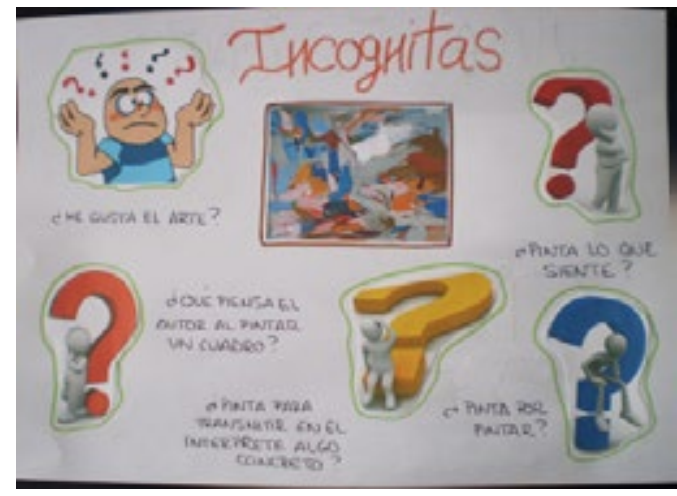

Figura 7. Anónimo: Incógnitas, 2013, collage, $29 \times 42 \mathrm{~cm}$. Fuente: Gómez-Redondo $(2013,594)$.

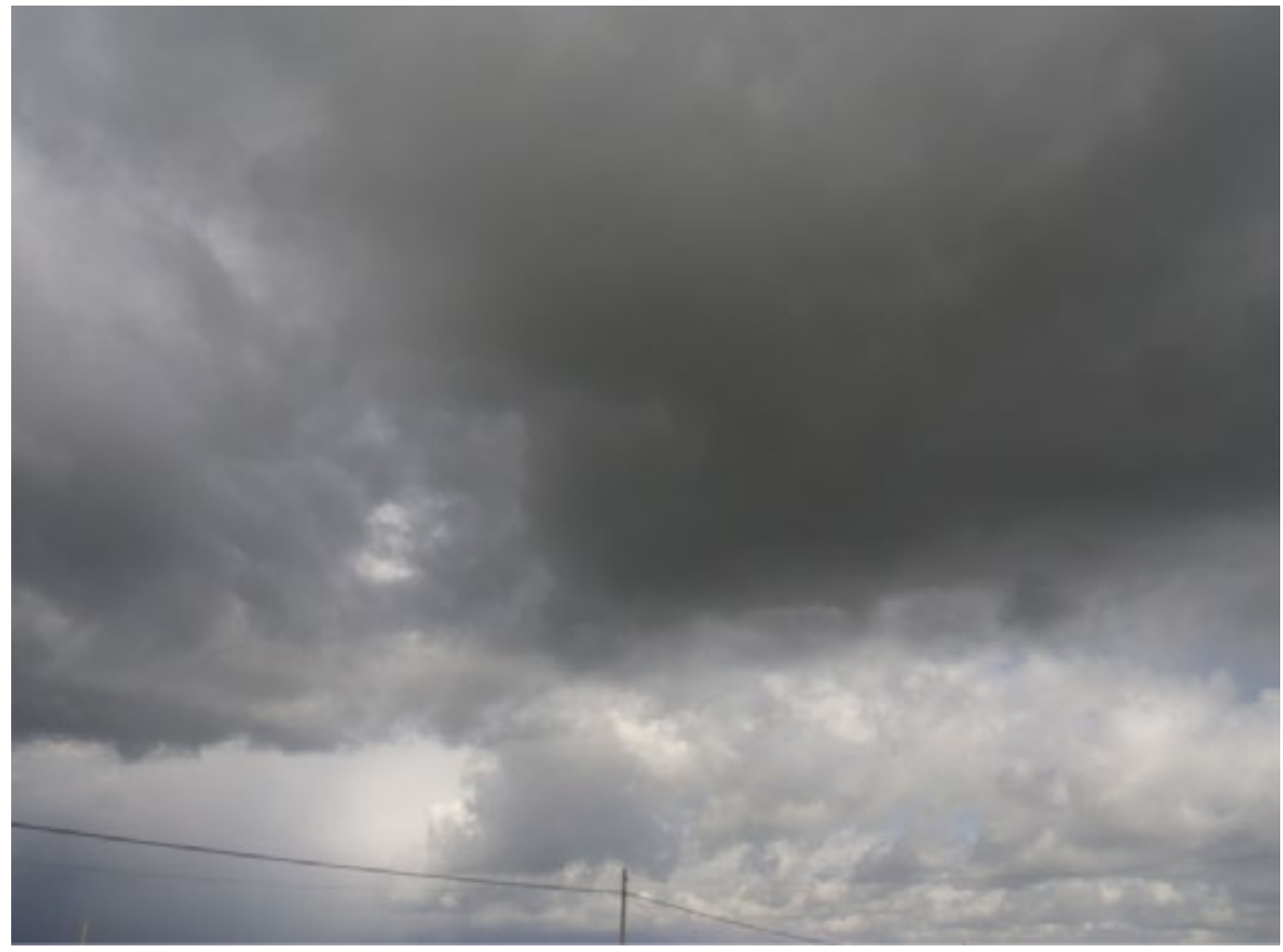

Figura 8. Anónimo: Manchas que nos unen, 2013.

Fuente: Gómez-Redondo $(2013,594)$ 


\section{LA IDEA DE COLECTIVIDAD COMO UNIÓN DE VARIAS PERSONAS}

Este concepto se materializa en imágenes como Somos un grupo, Buscando una identidad grupal o El enredo (figuras 8-10).

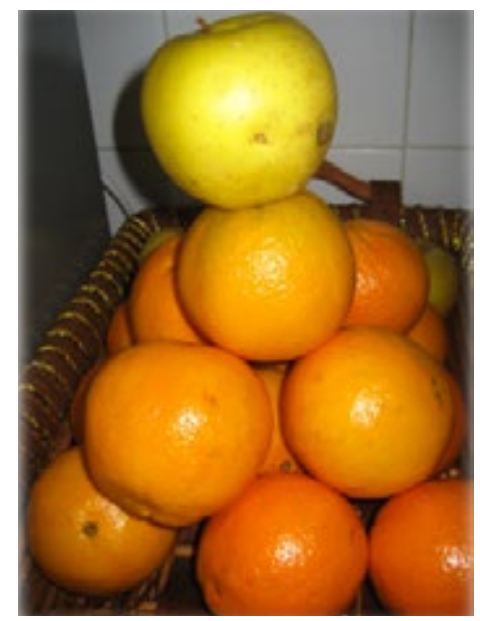

Figura 10. Anónimo: Buscando una identidad grupal, 2013 Fuente: Gómez-Redondo $(2013,593)$

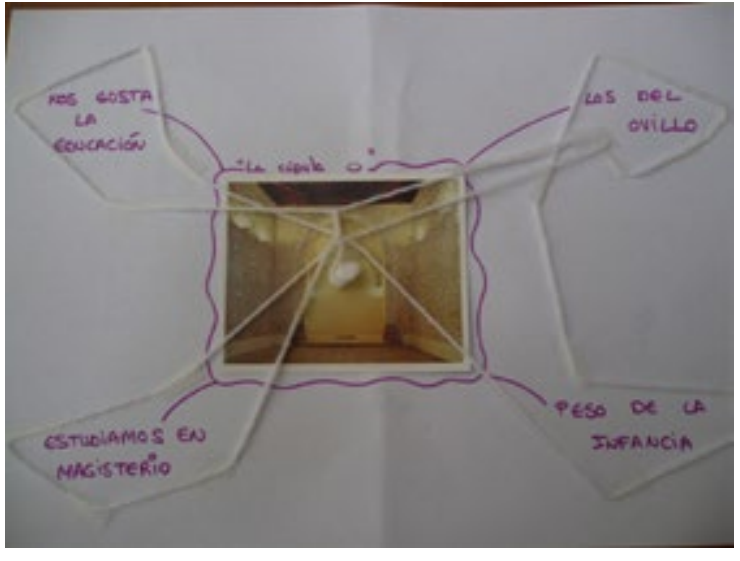

Figura 11. Anónimo: El enredo, 2013 Fuente: Gómez-Redondo $(2013,591)$.

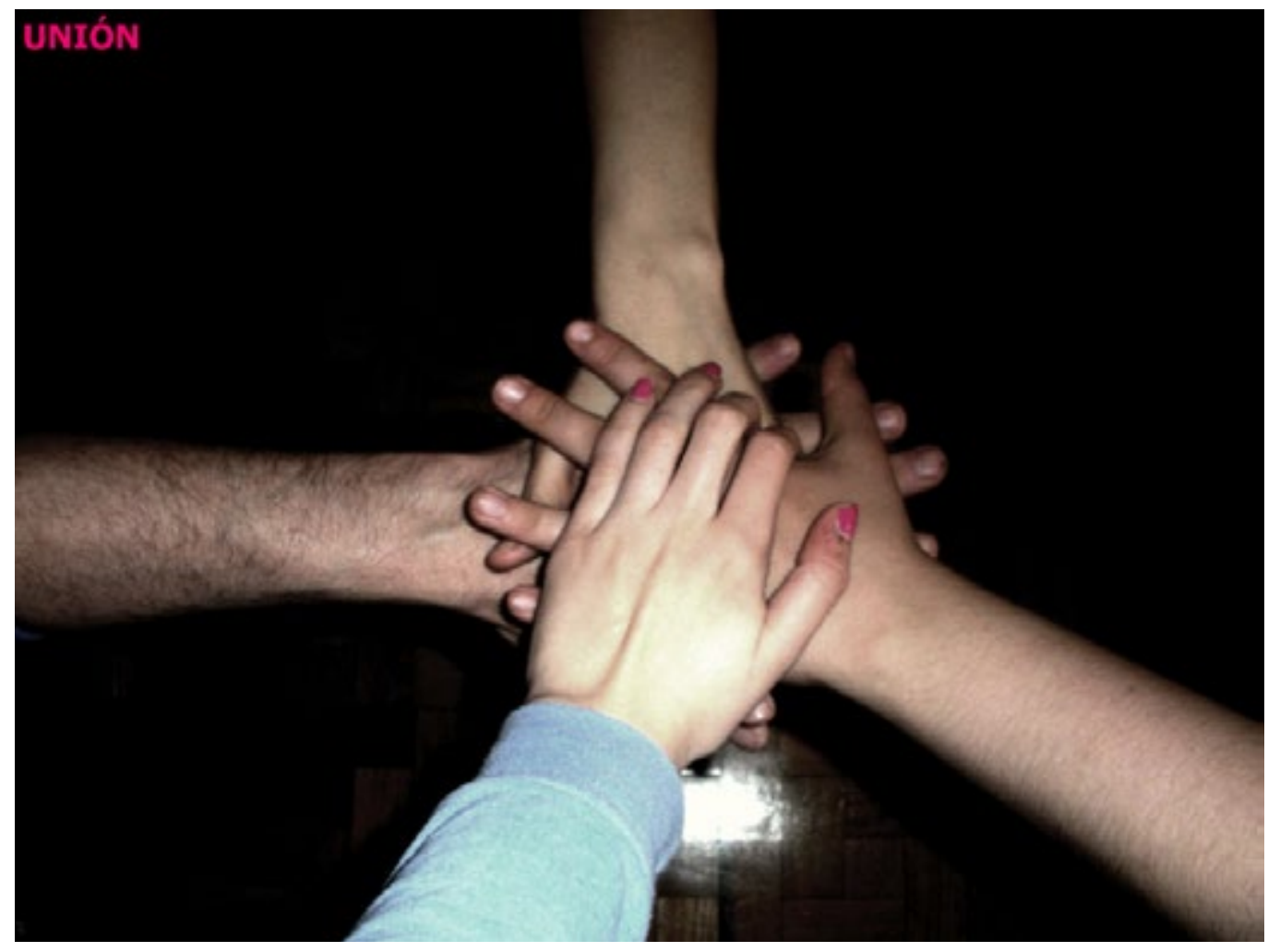

Figura 9. Anónimo: Somos un grupo, 2013 Fuente: Gómez-Redondo $(2013,591)$. 


\section{SEÑAS DE IDENTIDAD: EL OVILLO}

Una de las señas iniciales marcadas por el grupo fue el ovillo empleado como instrumento para la estrategia de presentación, lo cual queda representado en Los del ovillo, Solamente el ovillo o Foto del ovillo (figuras 11-13).

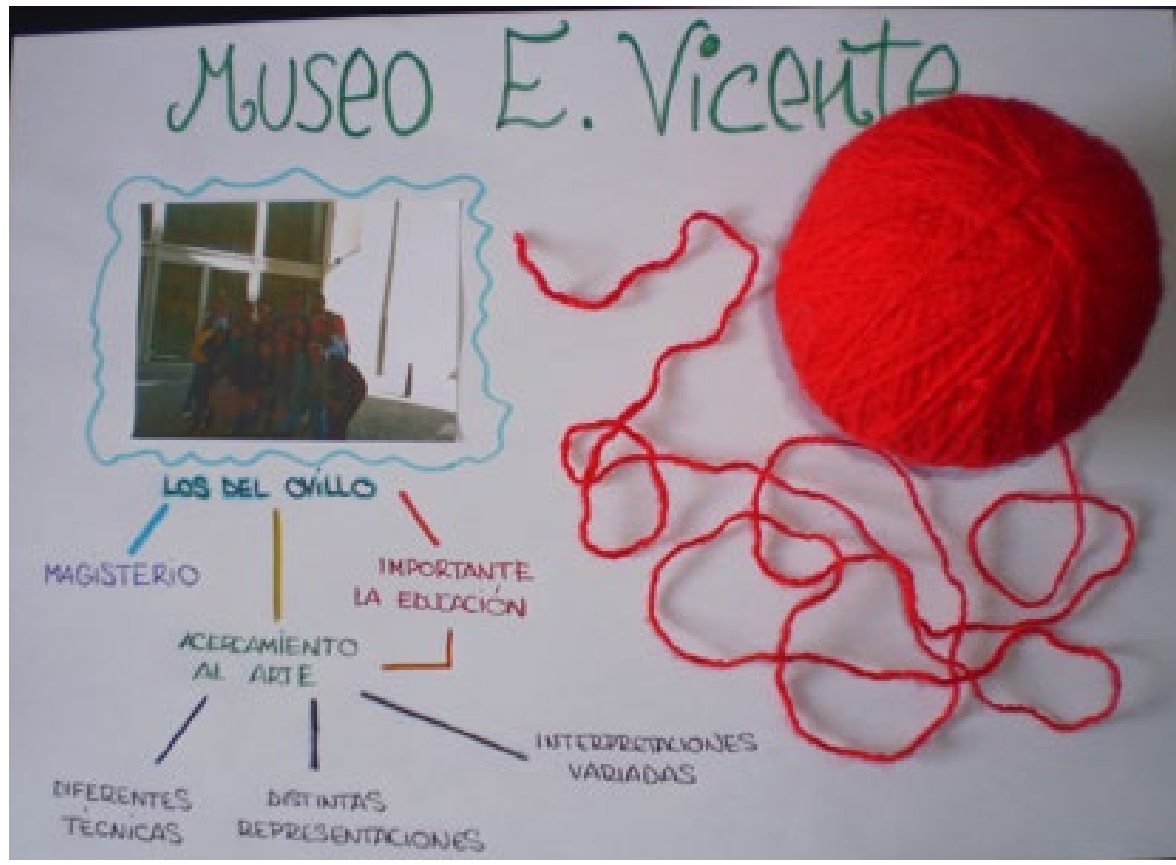

Figura 12. Anónimo: Los del ovillo, 2013, collage, $29 \times 42 \mathrm{~cm}$ Fuente: Gómez-Redondo (2013, 591).

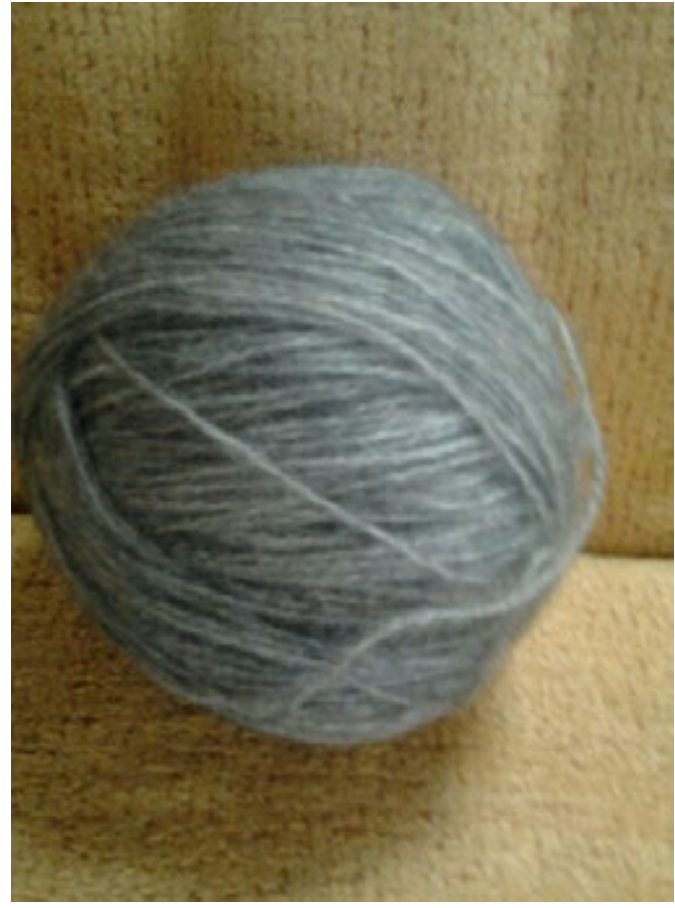

Figura 13. Anónimo: Solamente el ovillo, 2013. Fuente: Gómez-Redondo (2013, 600).

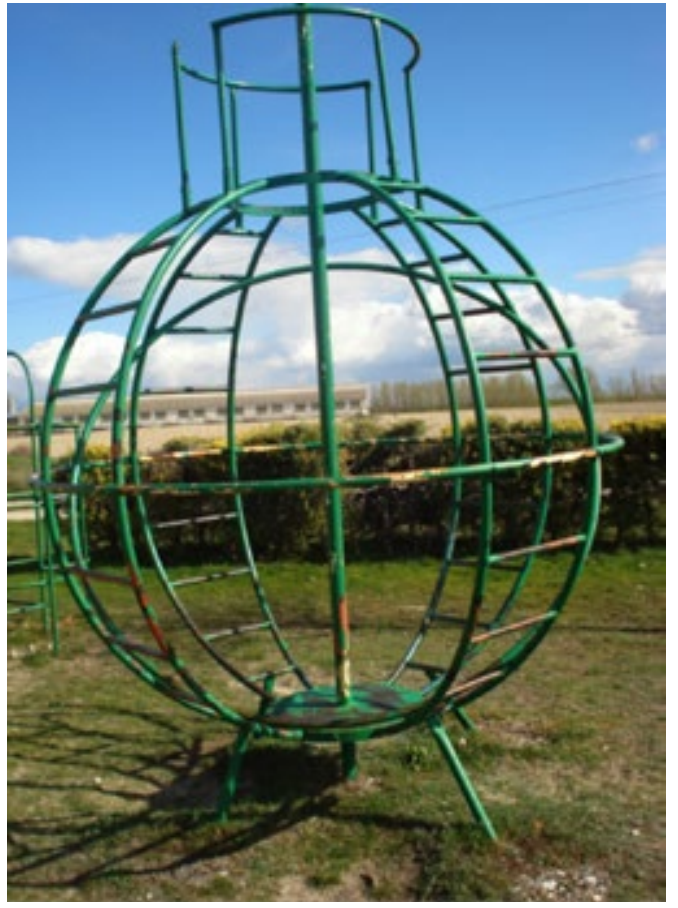

Figura 14. Anónimo: Foto del ovillo, 2013 Fuente: Gómez-Redondo $(2013,593)$ 


\section{SENNAS DE IDENTIDAD: SEGOVIA}

Otra seña de identidad nacida a partir de la realización de la cartografía es la que hace referencia a Segovia como punto inicial común por encima del Museo Esteban Vicente. Eso queda patente a través de narrativas como Un patrimonio en común, Alcázar de Segovia o 1 love Segovia. Resulta aquí interesante observar cómo, aunque no aparece una imagen con referencia explícita a la obra de Esteban Vicente, sí surgen otros elementos patrimoniales, más arraigados tradicionalmente en otra identidad colectiva (figuras 14-16).

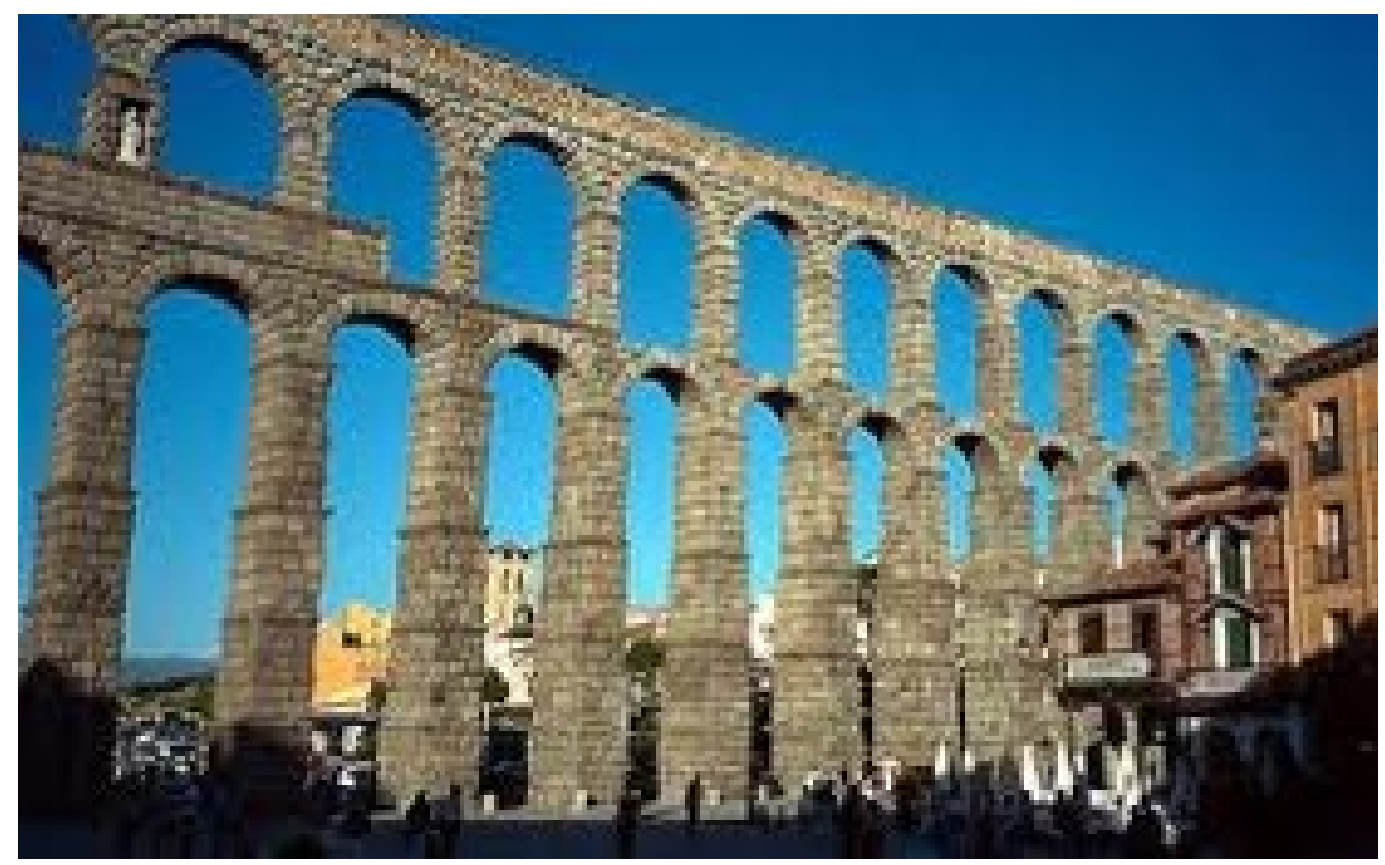

Figura 15. Anónimo: Un patrimonio en común, 2013. Fuente: Gómez-Redondo $(2013,598)$.

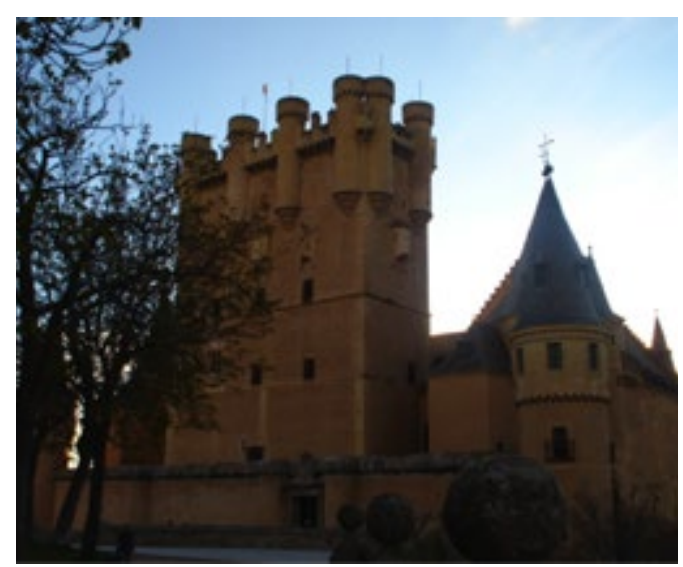

Figura 16. Anónimo: Alcázar de Segovia, 2013

Fuente: Gómez-Redondo $(2013,600)$.



Figura 17. Anónimo: I love Segovia, 2013. Fuente: Gómez-Redondo $(2013,599)$. 


\section{SEÑAS DE IDENTIDAD: LA INFANCIA Y LA JUVENTUD}

Uno de los conceptos que los define es la infancia como origen común a todos los miembros del grupo y la juventud como presente común; esto queda patente en imágenes como: Los niños, La inocente infancia o Fiesta, juventud, vida (figuras 17-19).

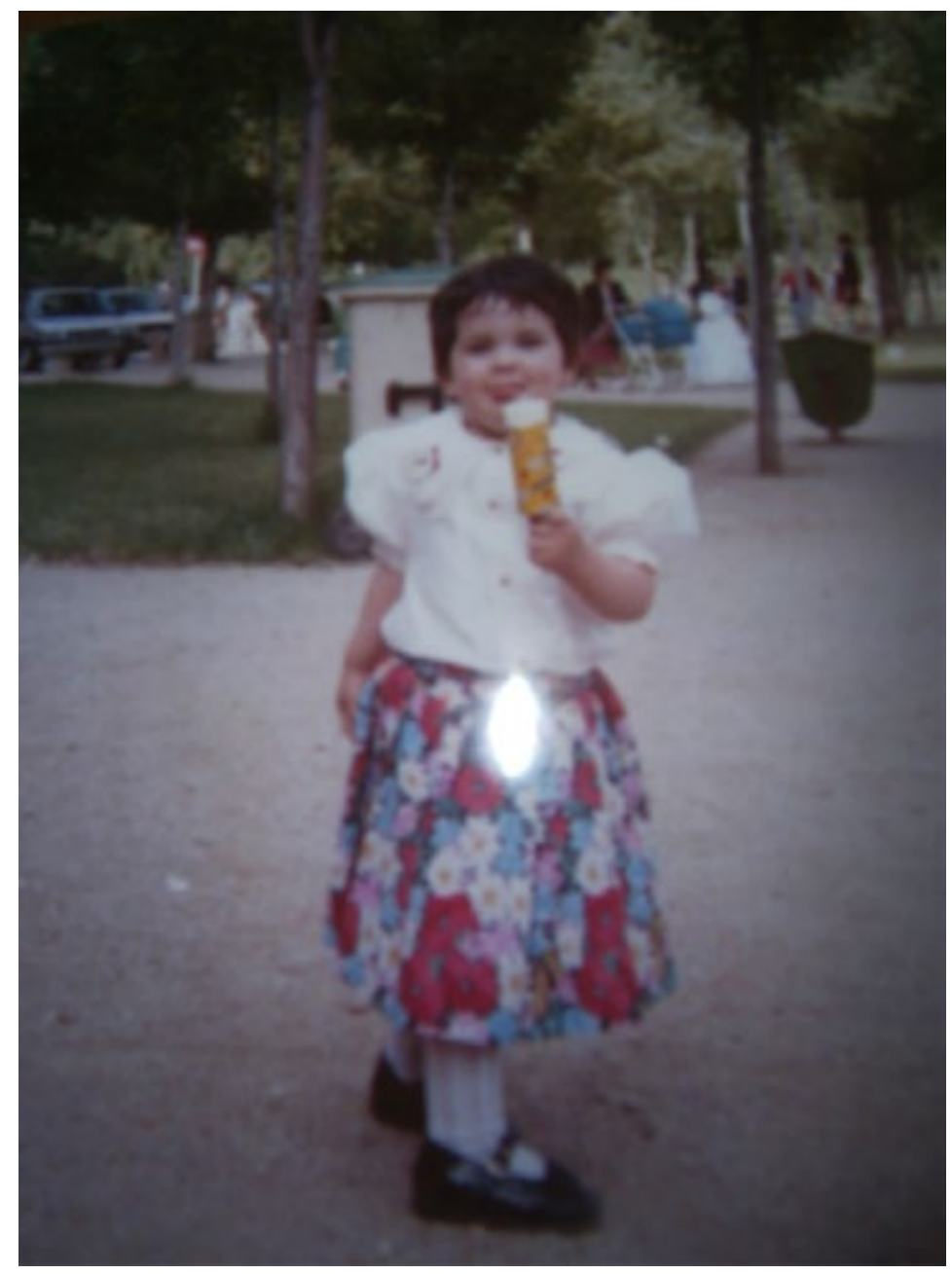

Figura 19. Gómez-Redondo (2013, 595).

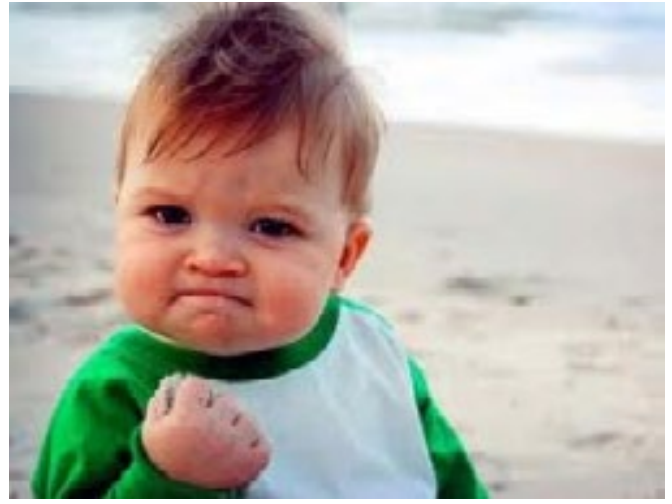

Figura 18. Anónimo: Los niños, 2013 Fuente: Gómez-Redondo $(2013,596)$

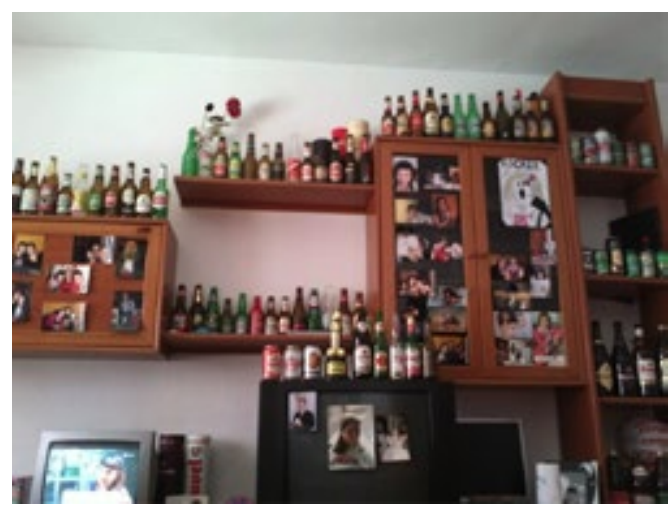

Figura 20. Anónimo, Fiesta, juventud, vida. 2013. Fuente: Gómez-Redondo (2013, 593). 


\section{SENAS DE IDENTIDAD: LA EDUCACIÓN}

Esta se perfiló al inicio del taller como una de las señas definitorias del grupo. Tal seña, aunque muy presente en las narrativas, no cuenta con un ámbito o campo propio, sino que sus imágenes se diseminan por toda la cartografía. Pasado y futuro, La educación o Multiculturalidad dan cuenta de ello (figuras 20-22).

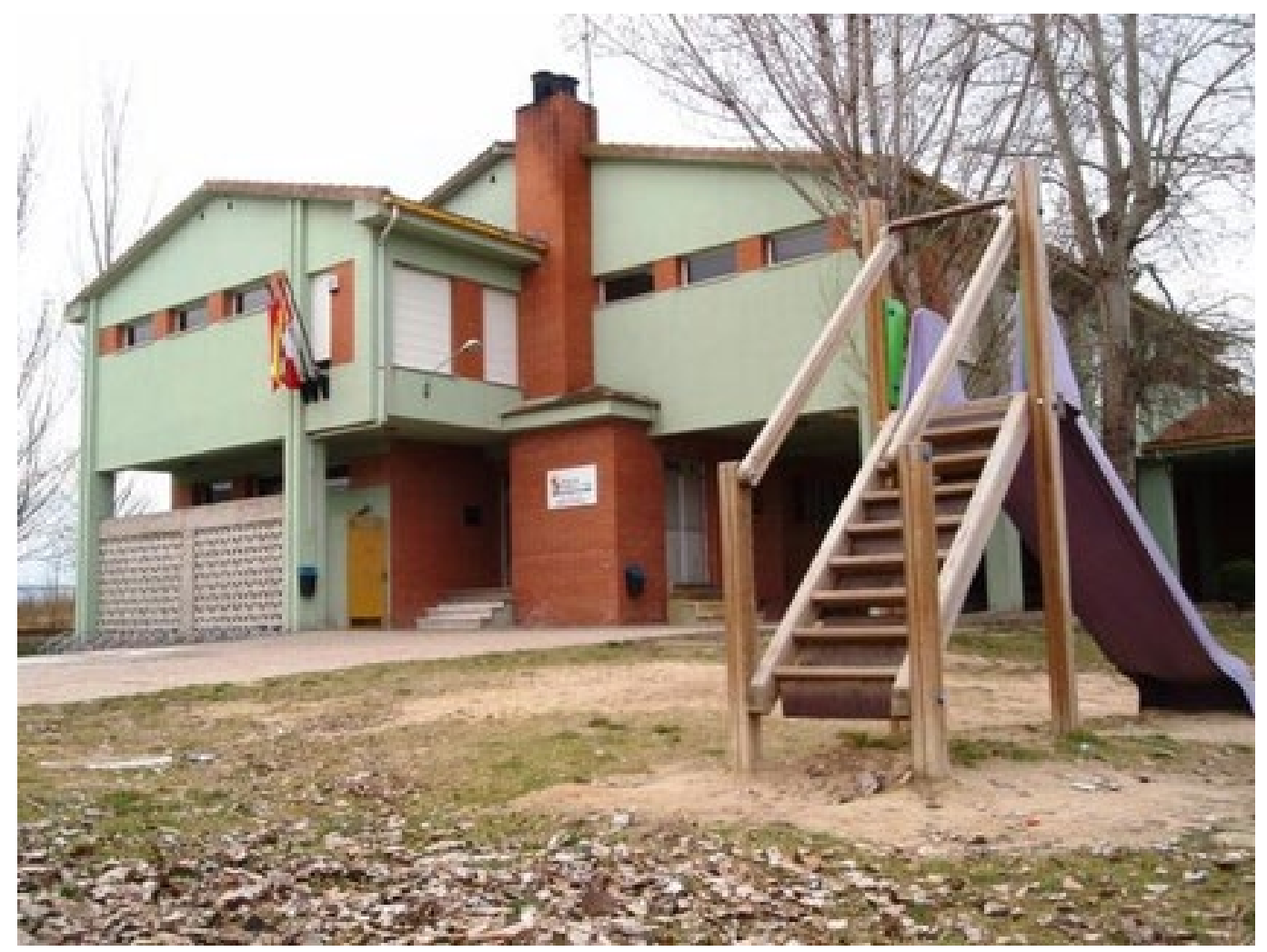

Figura 21. Anónimo: Pasado y futuro, 2013 Fuente: Gómez-Redondo $(2013,597)$.

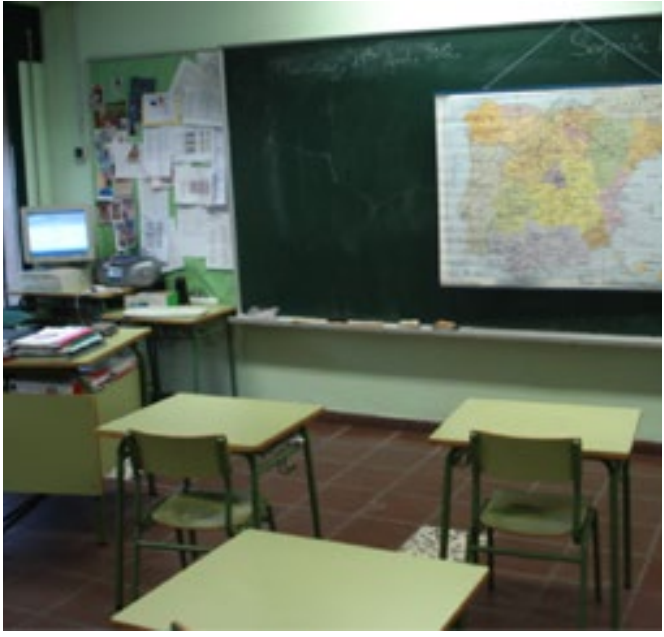

Figura 22. Anónimo: La educación, 2013. Fuente: Gómez-Redondo $(2013,600)$.

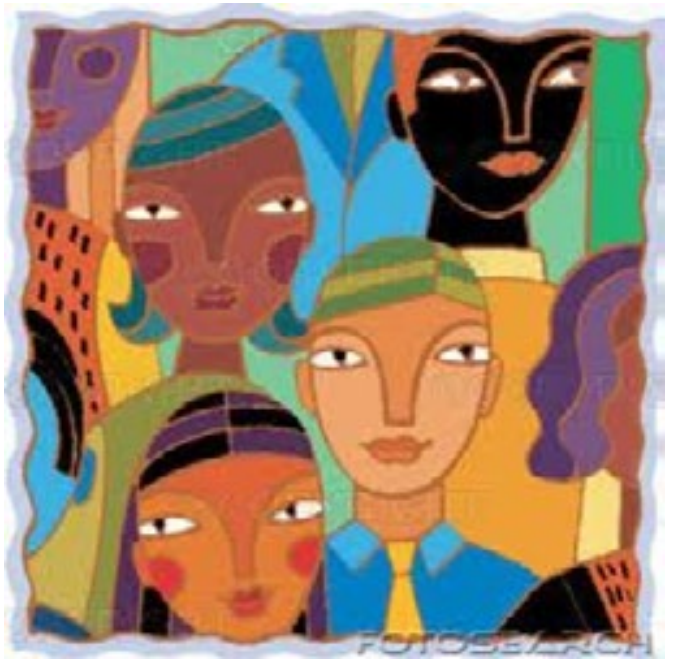

Figura 23. Anónimo, Multiculturalidad, 2013. Fuente: Gómez-Redondo $(2013,597)$. 
Queda patente un vínculo con la obra de Esteban Vicente que se estructura en su relación con el color, es decir, las diferentes narrativas que hacen referencia a la obra del autor lo hacen fundamentalmente en sus cualidades cromáticas. La obra de Vicente se establece en la mayoría de los casos como metáfora de los procesos identitarios del grupo, mucho más allá de la seña aislada. Aunque en numerosas narrativas aparecen referencias a la experiencia con la obra del artista, una mayoría parece concentrarse en un nodo aislado, como es el caso de Los sentimientos, Diferentes colores o Sentimientos del color (figuras 23-25).

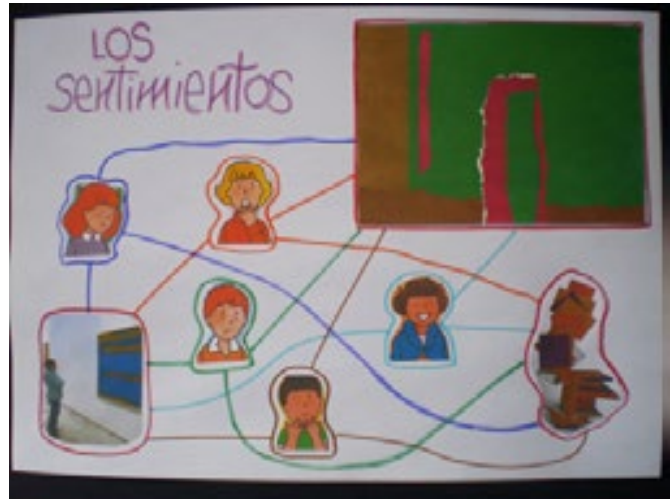

Figura 24. Anónimo: Los sentimientos, 2013, collage, $29 \times 42 \mathrm{~cm}$. Fuente: Gómez-Redondo $(2013,593)$

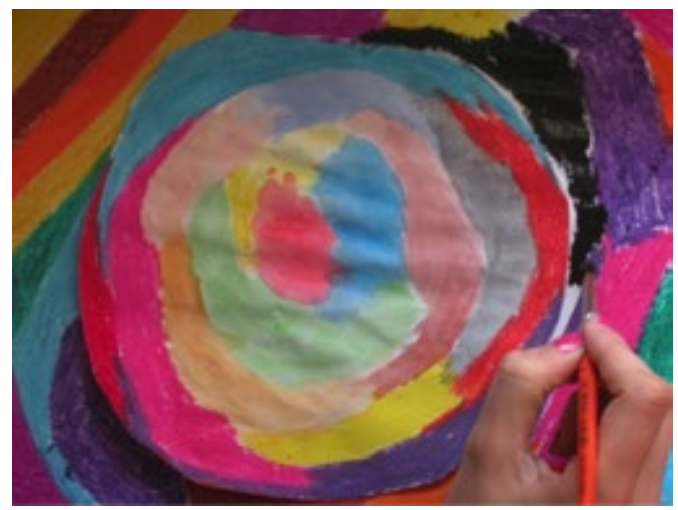

Figura 25. Anónimo: Diferentes colores, 2013, acuarela, 29x42 cm. Fuente: Gómez-Redondo $(2013,592)$

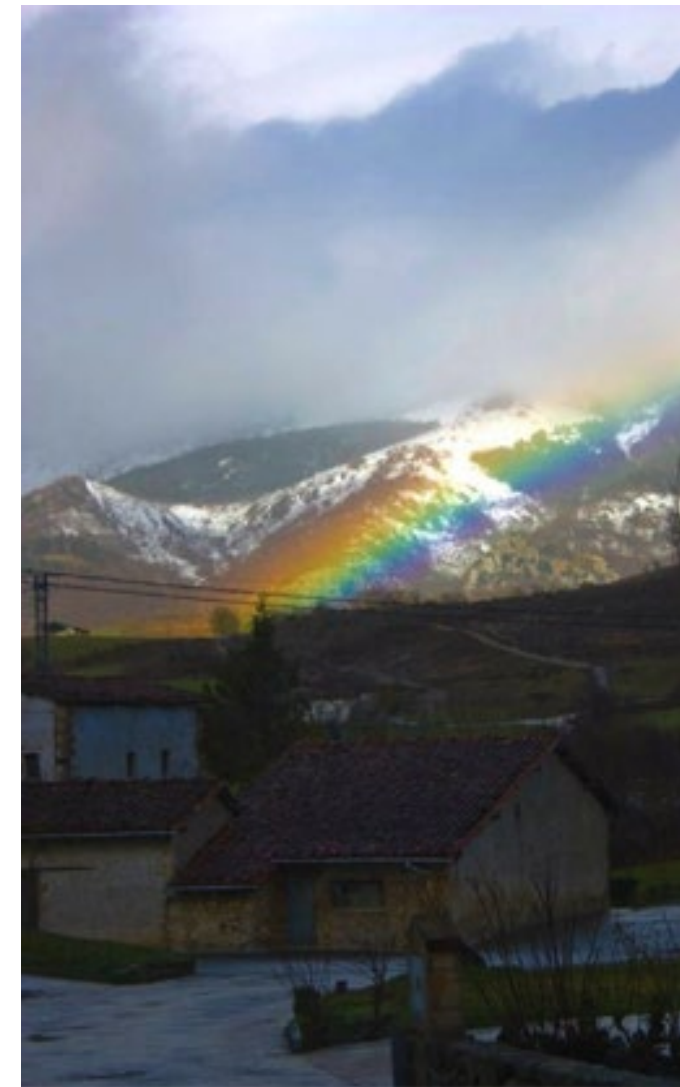

Figura 26. Anónimo: Sentimientos del color, 2013. Fuente: Gómez-Redondo $(2013,592)$. 
Existe, además, una relación conceptual implícita en algunas de las narrativas, pese a no tener conexiones evidentes; estos vínculos quedan evidenciados en la propia explicación de la imagen, como ocurre con la narrativa Foto del ovillo o el nodo que gira en torno a la obra de Esteban Vicente, pero que queda aislado de la cartografía y de lo explícitamente identitario.

Otra de las inercias observadas durante la construcción de la cartografía identitaria es la funcionalidad añadida de las imágenes que servían de detonante para nuevas narrativas de otros autores. Parece que el discurso inicial es definido, completado y relacionado con cada nueva aportación, dando lugar a un corpus identitario realizado de forma discursiva y discusiva.

Finalmente, podríamos decir que las narrativas más "vinculizadas" (Sánchez-Ferri 2016), es decir, las más consensuadas, son Los del ovillo, El enredo, Somos un grupo y Diferentes colores. Estas narrativas, tomadas como señas identitarias, no tanto en su contenido visual como discursivo, presentan evidencias de un proceso de identización en el seno del taller, la existencia de una identidad de grupo y la presencia de la obra de Esteban Vicente en esta identidad surgida.

De este modo, definiendo el grupo desde una narrativa externa, realizada a través del análisis de su cartografía identitaria, podríamos decir que existe un grupo, con una identidad propia, formada en el seno de un taller llevado a cabo en el Museo Esteban Vicente. Este grupo tiene muy presente su paso por el taller, y lo percibe como una experiencia significativa. El ideario que los define es el de personas con una infancia común, que viven su actual juventud de una forma activa y que tienen una común motivación futura por la educación. Todo ello los vincula a Segovia, que para ellos se define en sus monumentos emblemáticos. Además, son conscientes de que se construyen como grupo también cuando están fuera del grupo; por ello, aportan sus subjetividades e información sobre su experiencia individual. Y, como conclusión, a modo de sustancia suspensoria, la obra de Esteban Vicente es para ellos, más allá de una seña concreta, una metáfora de todo este proceso; así, se perciben como partes o colores de una obra, no concretada, de Esteban Vicente.

\section{CONCLUSIONES}

Para concluir este artículo, intentando generar un discurso homogéneo en el que se aúnen los conceptos teóricos tratados y la acción educativa llevada a cabo, podríamos enunciar que la acción educativa, entendida como instrumento para el aprendizaje significativo, resulta de gran valor y significatividad dentro de los procesos de patrimonialización y de identización individuales y colectivos. La acción educativa se configura como experiencia detonante de la identidad de grupo que se refuerza en las señas generadas y en los vínculos afectivos formados entre los participantes tomando las obras de arte como canal entre estos.

Para que esto ocurra, y como se ha observado en el desarrollo del taller, es preciso un proceso paralelo de patrimonialización que finalice en la identización, es decir, aquello que los participantes han significado como patrimonio se ha de configurar posteriormente como espacio para la relación identitaria entre los participantes y así generar una identidad de grupo en el arte. En este proceso, se patrimonializan, además, otras señas que se configuran como significativas para los participantes y es lo que hace de la acción educativa 
una experiencia identitaria.

En este contexto, el espacio virtual se muestra como un lugar neutro, en blanco, sobre el que volcar y construir ese imaginario identitario. Así pues, el diseño de la cartografía identitaria se presenta como actividad principal para la consecución de los objetivos en torno a los procesos de identización a través de la patrimonialización. Este espacio permite significar la experiencia del taller desde la cotidianidad de la vida de los participantes. Además, a través de su anacronía, dinamiza un flujo reflexivo y performativo de la identidad en construcción, de tal manera que, a la vez que se construye la cartografía, la identidad colectiva toma cuerpo y relevancia en la historia de los participantes y se aleja del hermetismo de los tradicionales talleres en el museo.

En el proceso de conformación identitaria, aparecen diversas dinámicas que se caracterizan por un carácter dialéctico, en las que cada individuo dialoga con el entorno, de tal forma que de esta dialéctica aparece el cambio y la mutación identitaria. Hablamos, pues, de “discusividad"/discursividad individual, pero también, y como ha ocurrido en el ARTEfacto, colectiva. Así pues, aparecen inercias hacia el consenso y la formación del grupo, en la propia conversación e interpretación de las obras, y también en la conformación de la cartografía identitaria, es decir, en el consenso de las señas de identidad.

Es el carácter discusivo lo que configura la dinamicidad y polisustancialidad de las identidades individuales y colectivas, y a través de la acción educativa este proceso se torna más consciente, reflexivo, creativo y agente. Los participantes se hacen conscientes de la voluntariedad de la identidad y gestionan su relación con el arte desde la afectividad y construyen comunidades con el arte. Esta vinculación identitaria y afectiva con el arte contemporáneo supone una forma de salvaguardia del patrimonio de hoy, y poniendo el protagonismo en el individuo, supone la generación de nuevos entornos de desarrollo social y personal en el seno de la cultura contemporánea.

\section{NOTAS}

1 Planteamos este término y sus derivados como variaciones del término discusión. De este modo, comprendemos que la discusividad es la capacidad de generarse en discusión con el entorno, el cambio a partir del diálogo. El término, por tanto, se aleja de discursividad que hace referencia al transcurso, es decir, al cambio a lo largo del tiempo y del espacio 


\section{REFERENCIAS}

Aguirre, Imanol. 2008. "Nuevas ideas de arte y cultura para nuevas perspectivas en la difusión del patrimonio". En El acceso al patrimonio cultural: retos y debates, coordinado por Imanol Agirre Arriaga, 67-118. Pamplona: Universidad Pública de Navarra.

Álvarez-Rodríguez, Dolores. 2007. "El museo como comunidad de aprendizaje." En Espacios estimulantes: museos y educación artística, editado por Ricard Huerta y Romá de la Calle, 109-127. Valencia: Universidad de Valencia.

Ballart, Xavier y Jordi Joan Tresserras. 2001. Gestión del patrimonio cultural. Barcelona: Ariel.

Gómez-Redondo, Carmen. 2011. “Identización: la construcción discursiva del individuo". Arte, Individuo y Sociedad 1 (24): 21-37.

Berger, Peter y Thomas Luckmann. 2001. La construcción social de la realidad. Buenos Aires: Amorrortu.

Calaf, Roser. 2009. Didáctica del patrimonio: epistemología, metodología y estudio de casos. Gijón: Trea.

Fontal, Olaia. 2003. La educación patrimonial: teoría y práctica para el aula, el museo e internet. Gijón: Trea.

Gómez-Redondo, Carmen. 2011. El arte contemporáneo: escenario para nuevas identidades. En Actas del II Congreso Internacional de arte, educación y cultura: aportaciones desde la periferia. Jaén: Colegio Oficial Bellas Artes Sevilla.

Gómez-Redondo, Carmen. 2013. Procesos de patrimonialización en el arte contemporáneo: diseño de un artefacto educativo para la identización (Tesis de doctorado, Universidad de Valladolid, Valladolid, España).

Hooper-Greenhill, Eilean. 1998. Los museos y sus visitantes. Gijón: Trea.

Levi, Albert William. 1985. "The art museum as an agency of culture." Journal of Aesthetic Ecucation 2 (19): $23-40$.

Meirinhos, Manuel y Antonio Osório. 2009. "Las comunidades virtuales de aprendizaje: el papel central de la colaboración". Pixel-Bit. Revista de Medios y Educación 35: 45-60.

Juanola, Roser y Montserrat Calbó. 2004. “Hacia modelos globales en educación artística”. En Comunicación educativa del patrimonio: referentes, modelos y ejemplos, coordinado por Roser Calaf Masachs y Olaia Fontal Merillas, 105-136. Gijón: Trea.

Rivière, Henri Georges. 1993. La museología: curso de museología/textos y testimonios. Madrid: Akal.

Rodrigo, Miguel Rodrigo. 2009. "La identidad como patchwork". I/C - Revista Científica de Información y Comunicación 6: 285-305.

Sánchez-Ferri, Ana. 2016. Memoria, identidad y comunidad: evaluación de programas de educación patrimonial en la Comunidad de Madrid (Tesis de doctorado, Universidad de Valladolid, Valladolid, España).

Valle Flórez, Rosa Eva. 2011. "Museos y diversidad: explorando con todos los sentidos," acceso el 25 de mayo de 2015,

http://docplayer.es/11249269-Museos-y-diversidad-explorando-con-todos-los-sentidos-rosa-eva-valle-florezuniversidad-de-leon-espana-dfcrvf-unileon-es.html

\section{Cómo citar este artículo:}

Gómez-Redondo \& Fontal. 2017. “Procesos de identización en el arte contemporáneo: construir una identidad colectiva a través de una cartografía identitaria en la red". Cuadernos de Música, Artes Visuales y Artes Escénicas 12 (2): 299-319. https://doi.org/10.11144/Javeriana.mavae12-2.piac 